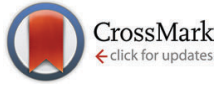

Cite this: J. Mater. Chem. B, 2016, 4, 3886

Received 11th January 2016, Accepted 3rd May 2016

DOI: $10.1039 / c 6 t b 00075 d$

www.rsc.org/MaterialsB

\title{
High nuclearity carbonyl clusters as near-IR contrast agents for photoacoustic in vivo imaging $\dagger$
}

\author{
Zhiyong Lam, $\ddagger^{\mathrm{ab}}$ Ghayathri Balasundaram $\ddagger^{\mathrm{b}}$ Kien Voon Kong, ${ }^{\mathrm{C}}$ Bo Yang Chor, ${ }^{\mathrm{a}}$ \\ Douglas Goh, ${ }^{b}$ Bahareh Khezri, ${ }^{a}$ Richard D. Webster, ${ }^{a}$ Weng Kee Leong ${ }^{* a}$ and \\ Malini Olivo*bd
}

\begin{abstract}
High nuclearity carbonyl clusters of ruthenium and osmium are found to exhibit good photoacoustic (PA) activity in the near-IR (NIR) region. Their potential as PA contrast agents for full body imaging has been demonstrated for the first time with mice; intravenous administration of the osmium carbonyl cluster $\mathrm{Na}_{2}\left[\mathrm{Os}_{10}\left(\mu_{6}-\mathrm{C}\right)(\mathrm{CO})_{24}\right]$ afforded up to a four-fold enhancement of the PA signal in various tissues. The cluster exhibits low toxicity, high stability and superior PA stability compared to the clinically approved NIR dye, indocyanine green.
\end{abstract}

\section{Introduction}

The advent of transition metal carbonyls in biological applications has partly been spurred on by the discovery that carbon monoxide (CO) is produced endogenously through heme catabolism and is a vital cell signaling mediator and regulator. ${ }^{1,2}$ It has been reported to induce vasorelaxation and exhibits anti-inflammatory and cytoprotective effects against disease pathology. ${ }^{2-5}$ The controlled and site-specific delivery of $\mathrm{CO}$ has become of intense research interest, and transition metal carbonyls have naturally become the frontrunners as CO-releasing molecules (CORMs). ${ }^{6-8}$ Metal carbonyls have also been of interest as anti-cancer agents, and in bioimaging applications using infrared (IR), Raman, and surfaceenhanced Raman spectroscopy (SERS). ${ }^{9-12}$ More recently, we have demonstrated the use of a water-soluble triosmium carbonyl cluster for in vivo imaging of the rat cerebral cortex vasculature via photoacoustic (PA) imaging. ${ }^{13}$

PA imaging is a hybrid imaging modality that combines the strengths of optical and acoustic imaging, i.e., strong optical contrast with high spatial resolution, and is being recognized as an attractive, non-invasive method for in vivo imaging. ${ }^{14-16}$ It is based on the generation of acoustic waves resulting from

\footnotetext{
${ }^{a}$ Division of Chemistry and Biological Chemistry, Nanyang Technological University, Singapore.E-mail: chmlwk@ntu.edu.sg

${ }^{b}$ Singapore Bioimaging Consortium, Agency for Science and Technology and Research ( $\left.A^{*} S T A R\right)$, Singapore

${ }^{c}$ Department of Chemistry, National Taiwan University, Taiwan

${ }^{d}$ School of Physics, National University of Ireland, Galway, Ireland

$\dagger$ Electronic supplementary information (ESI) available. See DOI: 10.1039/ c6tb00075d

\$ These authors contributed equally.
}

thermoelastic expansion following the absorption of light. ${ }^{16-18}$ Unlike modalities such as X-ray and positron emission tomography (PET), the use of non-ionizing radiation is safer for both the user and the subject. It also compares favourably with pure optical imaging modalities such as multiphoton microscopy, confocal microscopy and optical coherence tomography, which suffer from poor penetration depth as a result of the strong scattering by soft tissues. ${ }^{19-21}$ As a result, PA imaging has been used in a wide range of in vivo studies, including probing of dynamic changes in the hemoglobin oxygen saturation of skin, brain hemodynamic changes and tumor angiogenesis. ${ }^{22-24}$ Aside from the visualization of the distribution of endogenous molecules such as oxy- and deoxy-hemoglobin, exogenous contrast agents are often introduced for site-specific imaging. Various contrast agents have been developed, including single-walled carbon nanotubes, ${ }^{25}$ gold nanostructures, ${ }^{26,27}$ fluorescent proteins, ${ }^{28}$ cyanine dyes and, ${ }^{29}$ most recently as mentioned above, metal carbonyl clusters.

Although the PA contrast of the triosmium carbonyl cluster is high, a major drawback lies in the incident wavelength of $410 \mathrm{~nm}$; tissue penetration is low at this wavelength and thus an invasive procedure is required to carry out the imaging. A metal carbonyl that absorbs in the near-IR (NIR) range, from 680 to $1000 \mathrm{~nm}$, is more desirable as it will offer deeper tissue penetration and less scattering. We wish to report here that the optical absorption of the metal carbonyl clusters is shifted to longer wavelengths with an increase in the nuclearity of the metal core, and these high nuclearity carbonyl clusters (HNCC) show good PA activity in the NIR. A candidate compound has been found and demonstrated to be a good contrast agent for the full body imaging of small animals. 
a

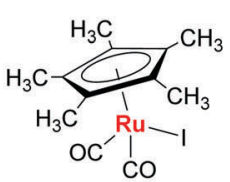

$\left(\eta^{5}-\mathrm{C}_{5} \mathrm{Me}_{5}\right) \mathrm{Ru}(\mathrm{CO})_{2} \mathrm{I}$

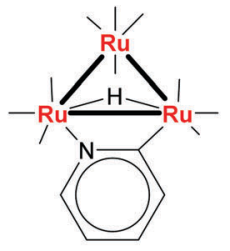

$\mathrm{Ru}_{3}(\mathrm{CO})_{10}(\mu-\mathrm{H})\left(\mu-\mathrm{NC}_{5} \mathrm{H}_{4}\right)$

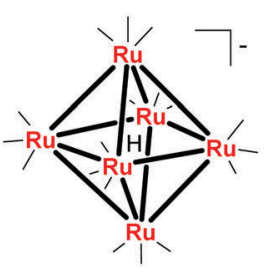

$\left[\left(\mathrm{Ph}_{3} \mathrm{P}\right)_{2} \mathrm{~N}\right]\left[\mathrm{Ru}_{6}\left(\mu_{6}-\mathrm{H}\right)(\mathrm{CO})_{18}\right]$

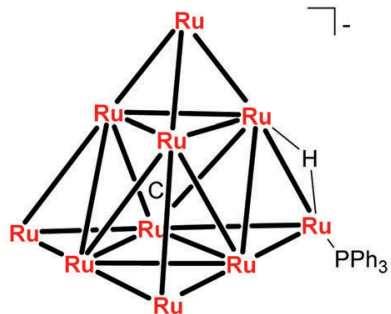

$\left[\mathrm{Ru}_{2}(\mu-\mathrm{H})\left(\mu-\mathrm{NC}_{5} \mathrm{H}_{4}\right)_{2}\left(\mathrm{CO}_{4}\left(\mathrm{NC}_{5} \mathrm{H}_{5}\right)_{2}\right]\right.$ $\left[\mathrm{Ru}_{10}(\mu-\mathrm{H})\left(\mu_{6}-\mathrm{C}\right)(\mathrm{CO})_{23}\left(\mathrm{PPh}_{3}\right)\right]$

4

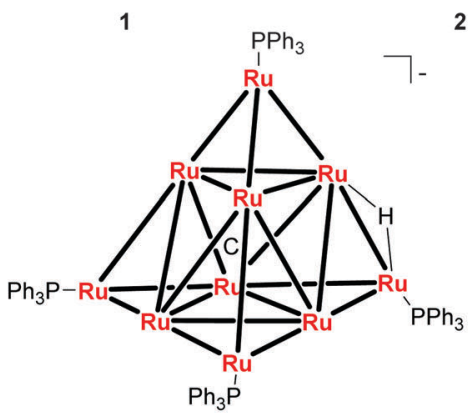

$\left[\mathrm{Ru}_{2}(\mu-\mathrm{H})\left(\mu-\mathrm{NC}_{5} \mathrm{H}_{4}\right)_{2}(\mathrm{CO})_{4}\left(\mathrm{PPh}_{3}\right)_{2}\right]$ $\left[\mathrm{Ru}_{10}(\mu-\mathrm{H})\left(\mu_{6}-\mathrm{C}\right)(\mathrm{CO})_{20}\left(\mathrm{PPh}_{3}\right)_{4}\right]$

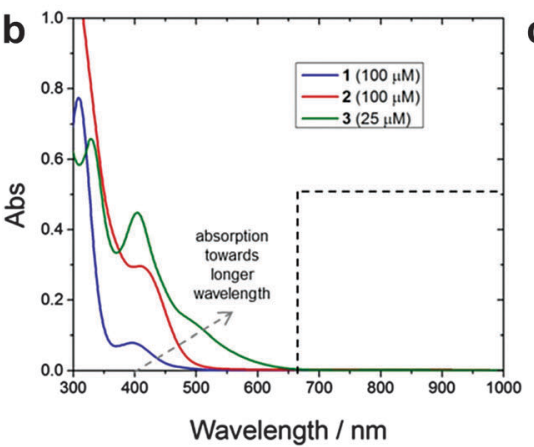

3

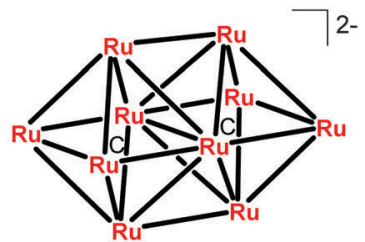

$\left[\left(\mathrm{Ph}_{3} \mathrm{P}\right)_{2} \mathrm{~N}_{3}\left[\mathrm{Ru}_{11} \mathrm{H}(\mathrm{CO})_{27}\right)\right]$

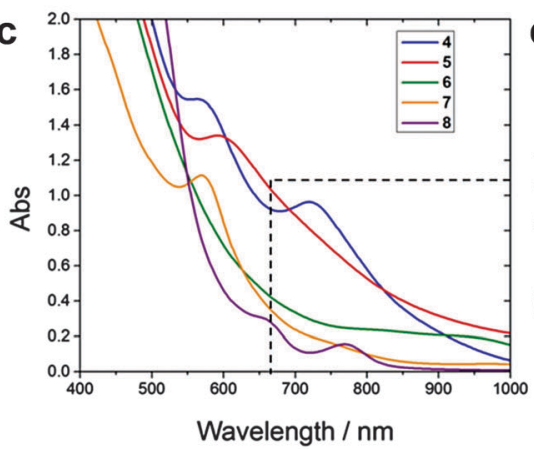

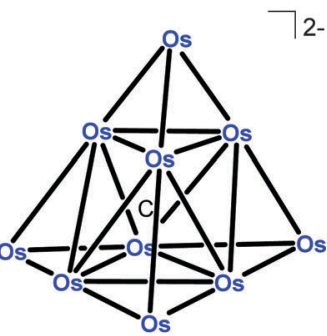

$\left[\left(\mathrm{Ph}_{3} \mathrm{P}\right)_{2} \mathrm{~N}_{2}\left[\mathrm{Os}_{10}\left(\mu_{6}-\mathrm{C}\right)(\mathrm{CO})_{24}\right]\right.$

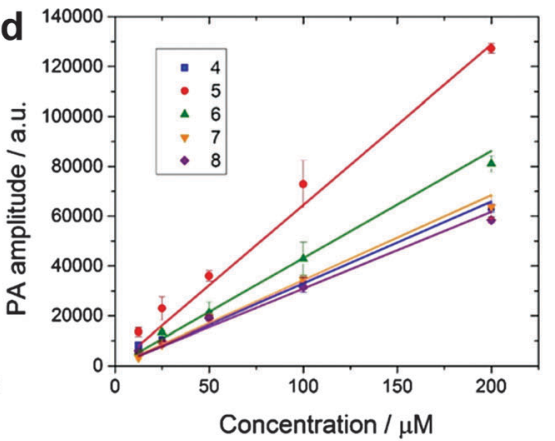

Fig. 1 (a) Molecular structures of 1-8. A line extending from the metal represents a CO ligand. Countercations and CO ligands in the HNCCs have been omitted for clarity. (b) Optical absorption spectra of 1-3 in DMSO at their respective concentrations. (c) Optical absorption spectra of 4-8 in DMSO at $200 \mu \mathrm{M}$. Boxed area represents the NIR region of interest. (d) Combined plot of PA amplitude as a function of concentrations of 4-8 in DMSO.

\section{Results and discussion}

\section{Optical and photoacoustic properties of metal carbonyls}

The absorption spectra of a number of ruthenium, and osmium, carbonyl complexes in a range of nuclearities were examined; these included homoleptic, as well as carbido, hydrido, and phosphinesubstituted derivatives, and with different metal core structures (Fig. 1a). While the low nuclearity compounds 1-3 did not show any absorption in the NIR region, all the HNCCs exhibited absorption in the NIR. In particular, there were distinct absorption maxima $\left(\lambda_{\max }\right)$ at 719 and $768 \mathrm{~nm}$ for clusters $\mathbf{4}$ and 8, respectively; the others showed broad shoulders tapering towards longer wavelengths (Fig. 1b and c). This latter broad and continuous absorption from the UV-visible to the NIR region has been attributed to the large number of "interband" transitions and hence the high degree of overlap of absorption bands. ${ }^{30}$ These absorptions have been assigned to $\mathbf{M}-\mathbf{C O} \sigma^{*} \leftarrow \pi$, as well as $\mathbf{M}-\mathbf{M} \sigma^{*} \leftarrow \sigma$ transitions, $^{30,31}$ and correspond to the HOMO-LUMO gap. For clusters 4-8,
Table 1 Optical absorption and PA properties of clusters 4-9 and indocyanine green (ICG)

\begin{tabular}{lllll}
\hline Entry & Compounds & $\lambda_{\max }{ }^{a} / \mathrm{nm}$ & $\varepsilon / \mathrm{M}^{-1} \mathrm{~cm}^{-1}$ & PA quantum yield \\
\hline $1^{b}$ & $\mathbf{4}$ & 719 & $4.52 \times 10^{3}$ & $329( \pm 20)$ \\
$2^{b}$ & $\mathbf{5}$ & $680^{e}$ & $4.81 \times 10^{3}$ & $644( \pm 19)$ \\
$3^{b}$ & $\mathbf{6}$ & $680^{e}$ & $1.87 \times 10^{3}$ & $431( \pm 24)$ \\
$4^{b}$ & 7 & $680^{e}$ & $1.46 \times 10^{3}$ & $342( \pm 12)$ \\
$5^{b}$ & $\mathbf{8}$ & 768 & $7.75 \times 10^{2}$ & $308( \pm 15)$ \\
$6^{b}$ & $\mathbf{9}$ & 770 & $9.08 \times 10^{2}$ & $315( \pm 35)$ \\
$7^{c}$ & $\mathbf{9}$ & 727 & $9.69 \times 10^{2}$ & $50( \pm 3)$ \\
$8^{d}$ & $\mathbf{9}$ & 760 & $8.41 \times 10^{2}$ & $87( \pm 5)$ \\
$9^{d}$ & ICG & 789 & $1.14 \times 10^{5}$ & $5097( \pm 157)$
\end{tabular}

${ }^{a}$ Within the NIR region of $680-900 \mathrm{~nm} .{ }^{b}$ In DMSO. ${ }^{c}$ In $10 \%$ DMSO in PBS $(\mathrm{v} / \mathrm{v}) .{ }^{d}$ In $10 \%$ DMSO in DMEM containing $10 \% \mathrm{FBS}, 1 \%$ L-glutamine and $1 \%$ penicillin/streptomycin (v/v). ${ }^{e}$ Absorption spectra showed only a broad shoulder tapering towards longer wavelengths in the $680-900 \mathrm{~nm}$ region, so $680 \mathrm{~nm}$ was chosen as it gave the highest absorption in the region.

absorption is negligible at $\geq 900 \mathrm{~nm}$, which suggests a HOMOLUMO gap on the order of $1.0 \mathrm{eV} .^{31-33}$ 


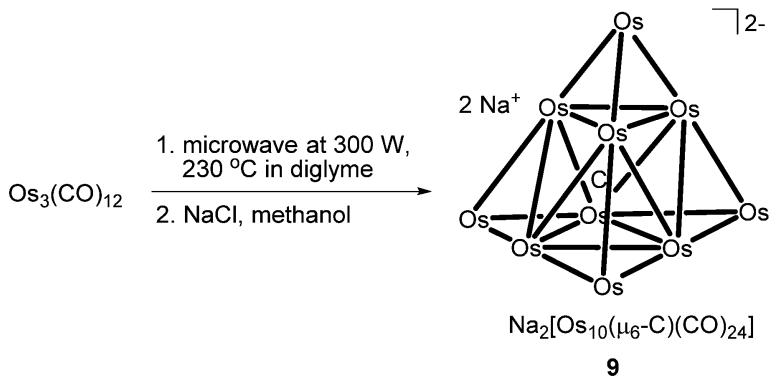

Scheme 1 Microwave-assisted synthesis of cluster 9. CO ligands have been omitted for clarity.

The PA activity of the five HNCCs was measured in a phantom, which mimics tissue optical properties. Strong PA signals were observed for all the clusters, with the PA intensity at their corresponding $\lambda_{\max }$ varying linearly with concentration (Fig. S2, ESI $\dagger$ ). The quantum yields (slope of the graph), a useful indicator of PA strength, were comparable, with the highest being that for $\mathbf{5}$ (Fig. 1d and Table 1). With the exception of 6 , the PA spectral intensity followed a similar trend to their optical spectra, indicating little or no decomposition.

\section{Synthesis of biocompatible cluster 9 and its photoacoustic properties in biological media}

The osmium cluster 8 was much more stable than the ruthenium clusters. Unfortunately, the $\left[\left(\mathrm{Ph}_{3} \mathrm{P}\right)_{2} \mathrm{~N}\right]^{+}$counterion exhibited very high cytotoxicity; we found an $\mathrm{IC}_{50}$ value of $1.1 \pm 0.4 \mu \mathrm{M}$ in an MTS assay against an oral squamous cell carcinoma (OSCC) cell line (Fig. S5, ESI $\dagger$ ). To increase the biocompatibility, the synthesis of $\left[\mathrm{Os}_{10}\left(\mu_{6}-\mathrm{C}\right)(\mathrm{CO})_{24}\right]^{2-}$ was modified to afford the sodium salt 9 (Scheme 1). ${ }^{34}$ This had a significantly lower toxicity, with an $\mathrm{IC}_{50}$ value of $83 \pm 2 \mu \mathrm{M}$ (Fig. S6, ESI $\dagger$ ). The molar extinction coefficients (at the $\lambda_{\max }$ ) of $\mathbf{9}$ in three different solvent compositions were found to be similar: (1) DMSO, (2) 10\% DMSO in phosphate buffer saline (PBS) (v/v), and (3) 10\% DMSO in Dulbecco's modified Eagle medium (DMEM) containing 10\% fetal bovine serum (FBS), 1\% L-glutamine and $1 \%$ penicillin/streptomycin (v/v). This was, however, not reflected in the PA response as the signal amplitude was higher in DMSO than in the aqueous biological media
(Fig. 2c and Table 1). That a stronger PA signal is found in organic solvents than in aqueous media has been reported for a number of contrast agents, and attributed to differences in the Grüneisen parameters that describe the solvent environment. ${ }^{35,36}$ Nevertheless, the PA signal of $\mathbf{9}$ in modified DMEM was sufficiently strong and remained detectable down to $12.5 \mu \mathrm{M}$.

\section{Chemical and photoacoustic stability of 9 , in comparison to indocyanine green}

Cluster 9 exhibits good chemical and PA stability in 10\% DMSO in modified DMEM; the absorbance at $\lambda_{\max }=760 \mathrm{~nm}$ remained consistent, and the CO vibrations at 2034 and $1988 \mathrm{~cm}^{-1}$ remained unchanged with consistent peak integrals, over a 7-day period (Fig. S7, ESI $\dagger$ ). The cluster was also incubated in modified DMEM for different lengths of time (10 min, 1, 3, 5 and 7 days) and then subjected to gel electrophoresis. The gel showed a similar dark red band for all time-points, indicating little or no decomposition (Fig. S8, ESI $\dagger$ ). The solution was also stable to irradiation at $760 \mathrm{~nm}$ over a period of $120 \mathrm{~min}$ (Fig. S9 and S10, ESI $\dagger$ ). In a comparative study with indocyanine green (ICG), we found that the latter has low PA stability although it has better optical and PA properties (Fig. S11, ESI $\dagger$ and Table 1); the PA signal decreased sharply upon irradiation at $790 \mathrm{~nm}$, and a similar decline was observed in its optical spectrum (Fig. S10, ESI $\dagger$ ). ICG is an organic tricarbocyanine NIR dye which has been approved by the U.S. Food and Drug Administration for clinical use in angiography, oncology and lymphatic vasculature imaging. ${ }^{37,38}$ Furthermore, there have also been many reports on its use in PA imaging, including through development into nano-sized constructs. ${ }^{39-42}$

\section{PA in vivo imaging of live mouse tumour models}

The potential of $\mathbf{9}$ as an exogenous contrast agent was assessed on three mice with OSCC xenografts; they were injected intravenously through the tail vein with a solution of 9 in $10 \%$ DMSO in heparinized saline $(200 \mu \mathrm{L}, 500 \mu \mathrm{M})$, giving an effective concentration of approximately $50 \mu \mathrm{M}$ upon dilution with blood in the animals. Abdominal scans were made before, and up to $24 \mathrm{~h}$ after, the injection using real-time multispectral optoacoustic tomography (MSOT). ${ }^{43}$ The reconstructed images
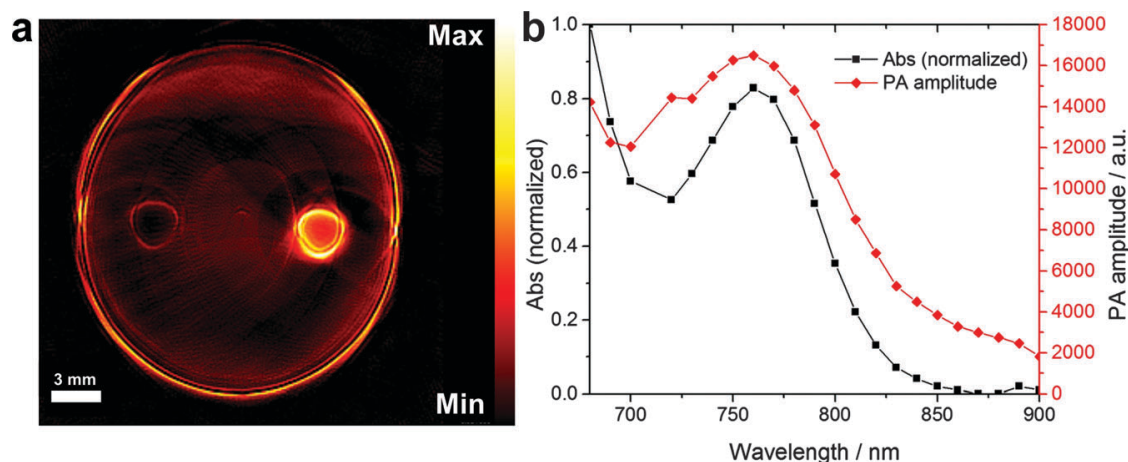

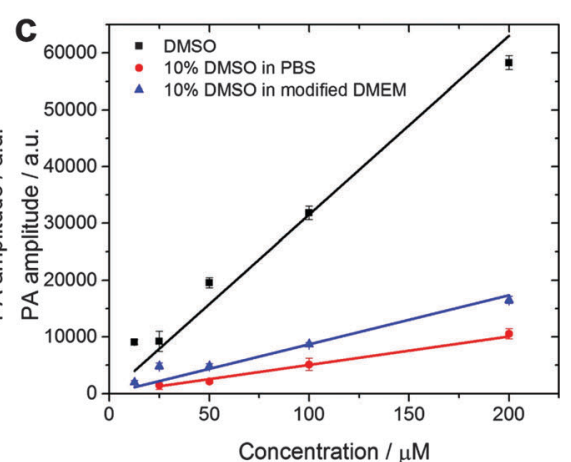

Fig. 2 (a) Optical absorption (black) and PA spectra (red) of $9(200 \mu \mathrm{M}, 10 \%$ DMSO in modified DMEM). (b) Single wavelength PA image of the phantom at $760 \mathrm{~nm}$. The right channel contains a solution of $\mathbf{9}(200 \mu \mathrm{M}, 10 \%$ DMSO in modified DMEM), while the left channel contains only the medium. (c) PA response of $\mathbf{9}$ as a function of concentration in three different solvent compositions. 
showed an increase in PA contrast in the liver, spleen and kidneys up to the first hour by up to 4-, 3- and more than 2-fold, respectively (Fig. 3a-c). This was reversed by the third hour, however, and almost reached baseline at $6 \mathrm{~h}$, suggesting fast clearance or breakdown of 9 in the body. As expected, there was no clear significant accumulation in the tumor in comparison to other tissues as $\mathbf{9}$ does not bear any tumor targeting ligand, although the tumor-to-muscle ratio of the PA signal intensity showed an apparent 5 -fold contrast at $3 \mathrm{~h}$ followed by a gradual decrease at 6 h (Fig. S13, ESI $\dagger$ ).

\section{Biodistribution of 9 in live mice}

The biodistribution of 9 inferred from the MSOT experiment has been corroborated by an analysis of the osmium contents, using inductively coupled plasma mass spectrometry (ICP-MS), after the mice were sacrificed at $24 \mathrm{~h}$ and $96 \mathrm{~h}$. Comparison of the values obtained at $24 \mathrm{~h}$ and $96 \mathrm{~h}$ reveals that the accumulation of osmium exists even after $96 \mathrm{~h}$, mostly in the liver and spleen, while the other organs showed a significant drop in the osmium content. The amount of osmium per tissue mass is significantly higher in the liver, spleen, lungs and kidneys than that in the control mice; it is highest in the liver, followed by the spleen (Fig. 3d and Fig. S14, ESI $\dagger$ ).

This is similar to what has been found with the more extensively studied gold nanoparticles; ${ }^{44-46}$ while there have been variations across the studies, in most of the cases, accumulation has been observed to be highest in the liver, followed by tumor, spleen or kidneys.

To further study the effect of the accumulation of osmium in the various organs (liver, spleen, liver, lungs and heart), the

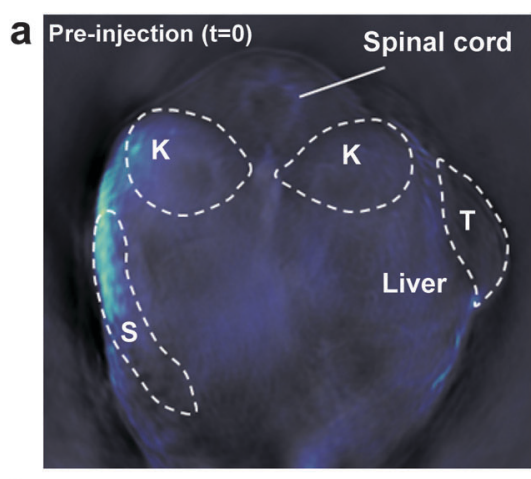

b

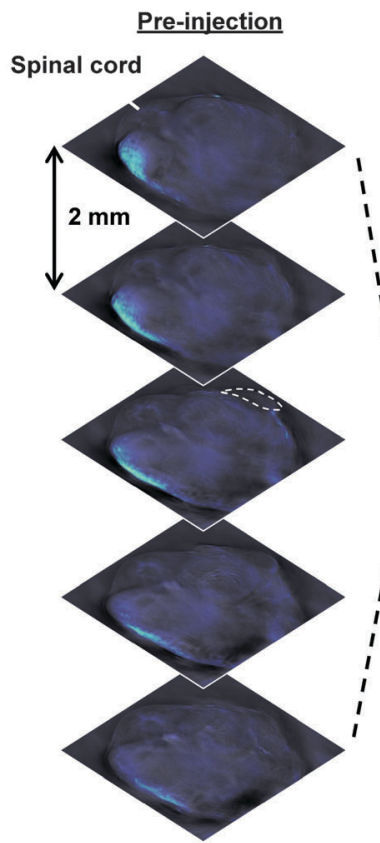

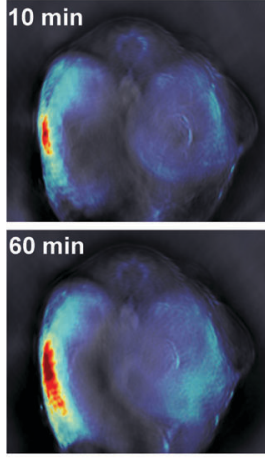

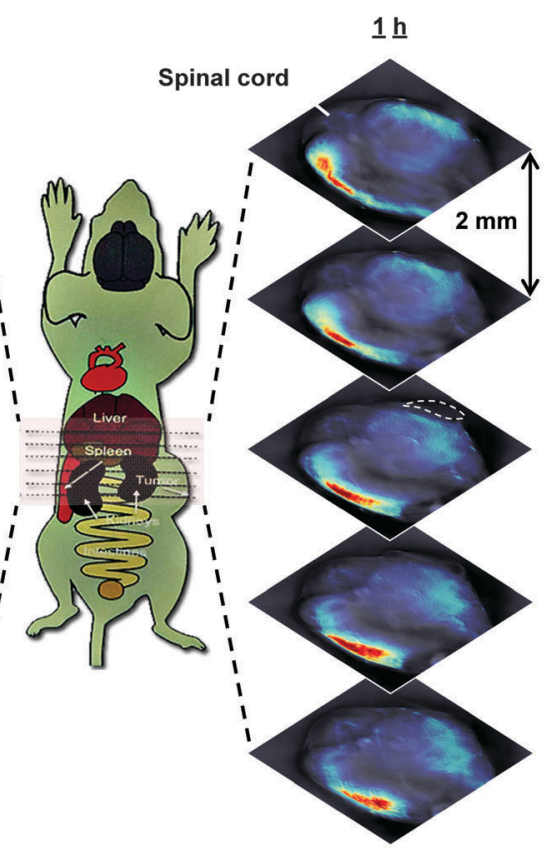

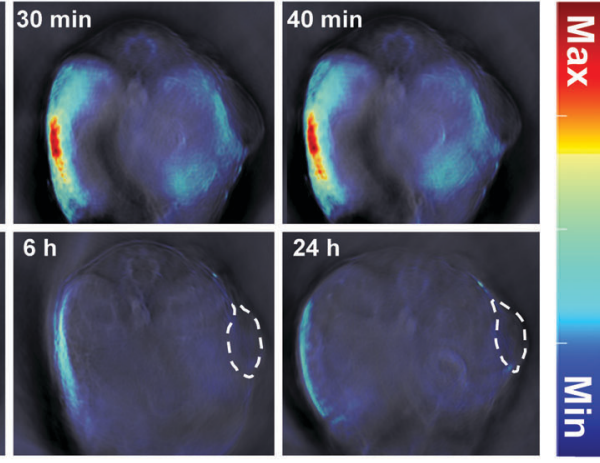

C

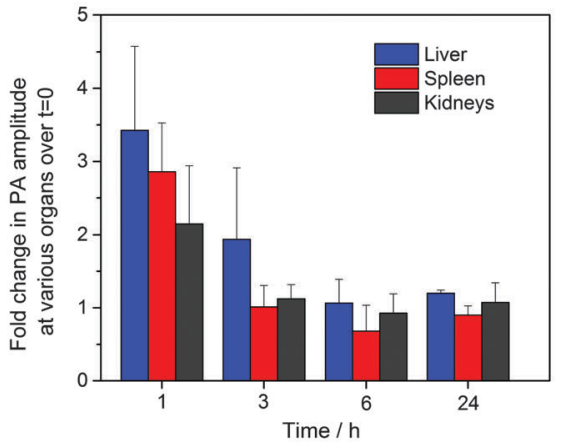

d

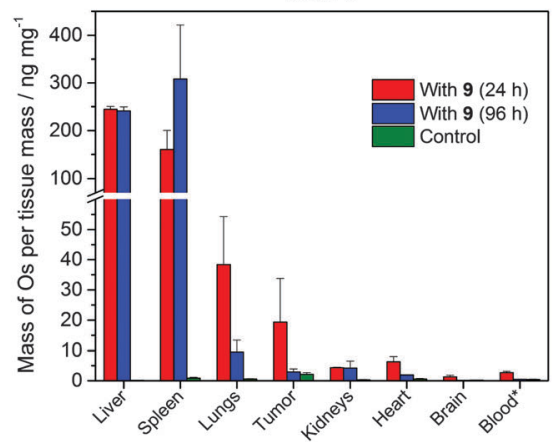

Fig. 3 In vivo PA imaging of the mouse OSCC xenograft model using $\mathbf{9}(200 \mu \mathrm{L}, 500 \mu \mathrm{M})$ as a contrast agent. (a) PA signal from 9 across a single slice of the mouse abdomen showing part of the liver, spleen (S), kidneys (K) and tumor (T) before and after injection up to $24 \mathrm{~h}$. All PA images are overlaid on their corresponding anatomy images at $800 \mathrm{~nm}$. Images depicting a greater portion of the liver can be found in Fig. S12 (ESI†). (b) Transverse sections of the mouse abdomen, at $2 \mathrm{~mm}$ interval, before and at $1 \mathrm{~h}$ after the injection of $\mathbf{9}$. (c) Fold change in the PA intensity in the liver, spleen and kidneys over that at $t=0$. (d) ICP-MS analysis of the amount of Os per tissue mass in various major organs of mice, $24 \mathrm{~h}$ and $96 \mathrm{~h}$ after injection of $\mathbf{9}$, with that of control samples. Error bars represent standard error of the mean, $n=3$ for samples with 9 (24 h) and $n=2$ for samples with 9 (96 h) and control samples. *Represented as mass of Os per fluid volume/ng $\mu \mathrm{L}^{-1}$. 


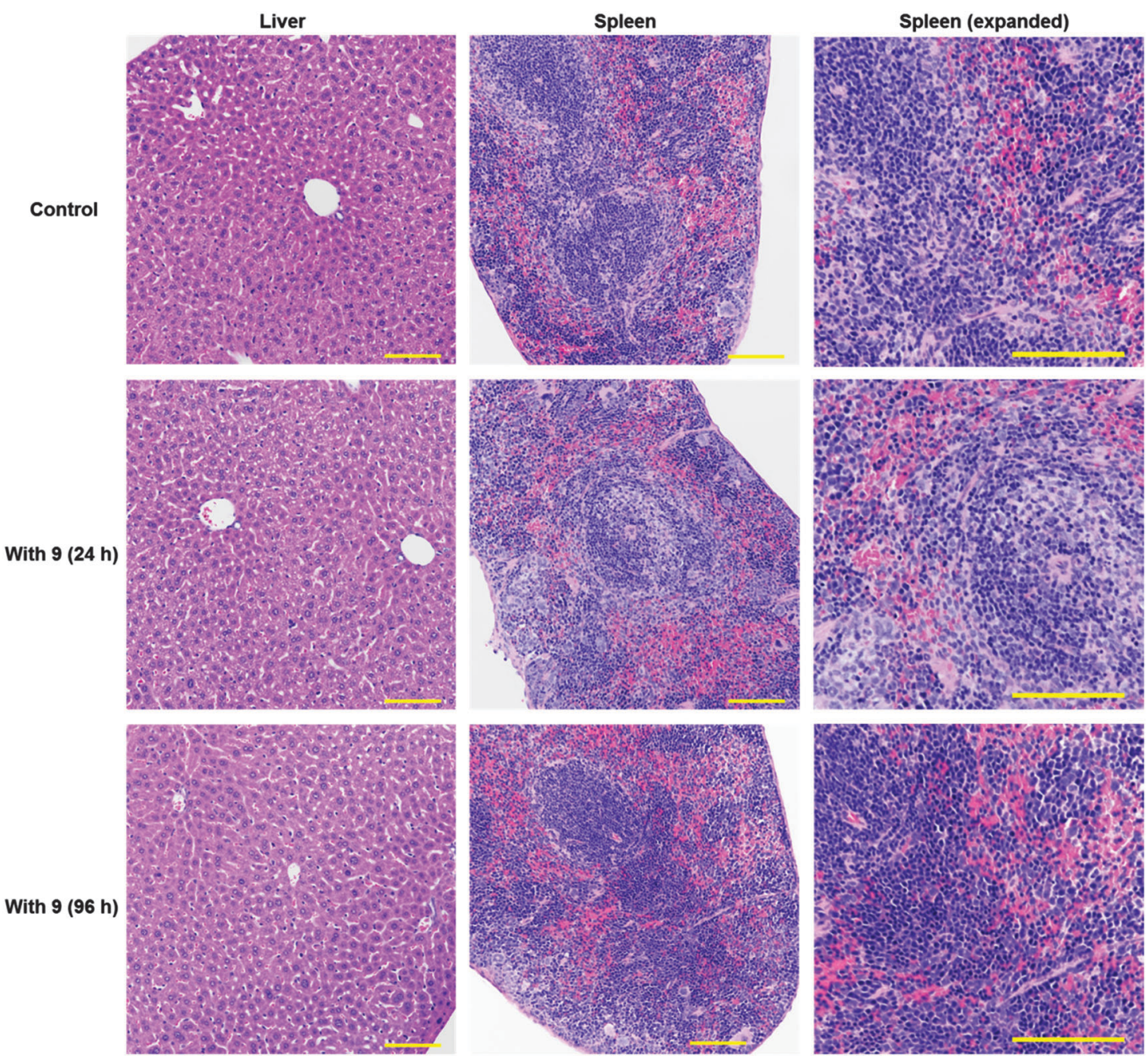

Fig. 4 Histopathology ( $\mathrm{H} \& \mathrm{E}$ staining) of liver and spleen tissues of mice, $24 \mathrm{~h}$ and $96 \mathrm{~h}$ after intravenous injection of 9, with that of control samples. Scale bar $=100 \mu \mathrm{m}$

mice were sacrificed at 24 and $96 \mathrm{~h}$ after injection of $\mathbf{9}$, and the tissue morphology of the organs analysed by histopathology. Hematoxylin and eosin (H \& E) staining of liver and spleen tissues displayed no obvious damage between the treated samples and control (Fig. 4), despite the accumulation of osmium. No visible abnormalities were also observed in the tissues of the kidneys, heart and lungs (Fig. S15, ESI $\dagger$ ). The condition and weight of the mice were also monitored over 24 and $96 \mathrm{~h}$, and mice administered with cluster 9 were well-conditioned and showed no sign of weight loss even after 96 h (Fig. S16, ESI $\dagger$ ). Nevertheless, the deposition of the osmium metal in the liver and spleen is of concern and will require a long-term study in the future.

\section{Conclusion}

We have shown in this work that the absorbance of metal carbonyl clusters was shifted towards the NIR on going from low to high nuclearity. This shift in the absorbance with nuclearity is a useful parameter for fine-tuning in optical applications. The low toxicity and the chemical- and photo-stability of $\mathbf{9}$ allowed for prolonged monitoring of its bio-distribution; both the time-lapsed PA images and ICP-MS analyses were indicative of distribution of the cluster via normal metabolism. These results suggest that HNCCs such as 9 are potentially useful PA contrast agents for deep tissue imaging. The next stage of development will be towards even better biocompatibility and PA response, and targeted imaging by exploiting the conjugation of targeting ligands to HNCCs via the reactivity of 9 to electrophiles or phosphine substitution.

\section{Experimental section}

Detailed description of the experimental procedures can be found in the ESI. $\dagger$

\section{Acknowledgements}

This work was supported by the Bio-Optical Imaging Group of Singapore Bioimaging Consortium, Agency for Science, Technology, 
and Research (SBIC, A*STAR) and by the Nanyang Technological University. Z. L. and B. Y. C. were supported by the $A^{*}$ STAR graduate scholarship. Histology work was performed by the Advanced Molecular Pathology Laboratory, Institute of Molecular and Cell Biology (IMCB, A*STAR) with the images acquired in the SBIC-Nikon Imaging Centre at Biopolis.

\section{References}

1 R. Tenhunen, H. S. Marver and R. Schmid, Proc. Natl. Acad. Sci. U. S. A., 1968, 61, 748-755.

2 R. Motterlini and L. E. Otterbein, Nat. Rev. Drug Discovery, 2010, 9, 728-743.

3 R. Wang, Z. Wang and L. Wu, Br. J. Pharmacol., 1997, 121, 927-934.

4 L. E. Otterbein, Antioxid. Redox Signaling, 2002, 4, 309-319.

5 J. Boczkowski, J. J. Poderoso and R. Motterlini, Trends Biochem. Sci., 2006, 31, 614-621.

6 C. C. Romao, W. A. Blattler, J. D. Seixas and G. J. L. Bernardes, Chem. Soc. Rev., 2012, 41, 3571-3583.

7 R. D. Rimmer, A. E. Pierri and P. C. Ford, Coord. Chem. Rev., 2012, 256, 1509-1519.

8 S. García-Gallego and G. J. L. Bernardes, Angew. Chem., Int. Ed., 2014, 53, 9712-9721.

9 H. Z. S. Lee, W. K. Leong, S. Top and A. Vessières, ChemMedChem, 2014, 9, 1453-1457.

10 K. V. Kong, W. Chew, L. H. K. Lim, W. Y. Fan and W. K. Leong, Bioconjugate Chem., 2007, 18, 1370-1374.

11 K. V. Kong, Z. Lam, W. D. Goh, W. K. Leong and M. Olivo, Angew. Chem., Int. Ed., 2012, 51, 9796-9799.

12 K. Meister, J. Niesel, U. Schatzschneider, N. Metzler-Nolte, D. A. Schmidt and M. Havenith, Angew. Chem., Int. Ed., 2010, 49, 3310-3312.

13 K. V. Kong, L.-D. Liao, Z. Lam, N. V. Thakor, W. K. Leong and M. Olivo, Chem. Commun., 2014, 50, 2601-2603.

14 C. Kim, C. Favazza and L. V. Wang, Chem. Rev., 2010, 110, 2756-2782.

15 V. Ntziachristos and D. Razansky, Chem. Rev., 2010, 110, 2783-2794.

16 L. V. Wang and H.-I. Wu, in Biomedical Optics: Principles and Imaging, John Wiley \& Sons, Inc., Hoboken, NJ, USA, 2009, pp. 283-321.

17 J. Xia, J. Yao and L. V. Wang, Prog. Electromagn. Res., 2014, 147, 1-22.

18 M. Xu and L. V. Wang, Rev. Sci. Instrum., 2006, 77, 041101.

19 R. H. Webb, in Methods Enzymol., ed. P. M. Conn, Academic Press, San Diego, 1999, vol. 307, pp. 3-20.

20 F. Helmchen and W. Denk, Nat. Methods, 2005, 2, 932-940.

21 E. M. Frohman, J. G. Fujimoto, T. C. Frohman, P. A. Calabresi, G. Cutter and L. J. Balcer, Nat. Clin. Pract. Neurol., 2008, 4, 664-675.

22 H. F. Zhang, K. Maslov, G. Stoica and L. V. Wang, Nat. Biotechnol., 2006, 24, 848-851.

23 X. Wang, Y. Pang, G. Ku, X. Xie, G. Stoica and L. V. Wang, Nat. Biotechnol., 2003, 21, 803-806.
24 G. Ku, X. Wang, X. Xie, G. Stoica and L. V. Wang, Appl. Opt., 2005, 44, 770-775.

25 A. De La Zerda, C. Zavaleta, S. Keren, S. Vaithilingam, S. Bodapati, Z. Liu, J. Levi, B. R. Smith, T.-J. Ma, O. Oralkan, Z. Cheng, X. Chen, H. Dai, B. T. Khuri-Yakub and S. S. Gambhir, Nat. Nanotechnol., 2008, 3, 557-562.

26 X. Yang, S. E. Skrabalak, Z.-Y. Li, Y. Xia and L. V. Wang, Nano Lett., 2007, 7, 3798-3802.

27 M. Eghtedari, A. Oraevsky, J. A. Copland, N. A. Kotov, A. Conjusteau and M. Motamedi, Nano Lett., 2007, 7, 1914-1918.

28 D. Razansky, M. Distel, C. Vinegoni, R. Ma, N. Perrimon, R. W. Koster and V. Ntziachristos, Nat. Photonics, 2009, 3, 412-417.

29 T. Temma, S. Onoe, K. Kanazaki, M. Ono and H. Saji, J. Biomed. Opt., 2014, 19, 090501.

30 M. P. Cifuentes, M. G. Humphrey, J. E. McGrady, P. J. Smith, R. Stranger, K. S. Murray and B. Moubaraki, J. Am. Chem. Soc., 1997, 119, 2647-2655.

31 S. R. Drake, B. F. G. Johnson, J. Lewis and R. G. Woolley, Inorg. Chem., 1987, 26, 3952-3956.

32 R. E. Benfield, in Physics and Chemistry of Metal Cluster Compounds, ed. L. J. De Jongh, Springer, Netherlands, 1994, vol. 18, pp. 249-275.

33 C. Femoni, M. C. Iapalucci, F. Kaswalder, G. Longoni and S. Zacchini, Coord. Chem. Rev., 2006, 250, 1580-1604.

34 K. D. Johnson and G. L. Powell, J. Organomet. Chem., 2008, 693, 1712-1715.

35 Y.-S. Chen, W. Frey, S. Aglyamov and S. Emelianov, Small, 2012, 8, 47-52.

36 Y.-S. Chen, W. Frey, S. Kim, P. Kruizinga, K. Homan and S. Emelianov, Nano Lett., 2011, 11, 348-354.

37 J. T. Alander, I. Kaartinen, A. Laakso, T. Pätilä, T. Spillmann, V. V. Tuchin, M. Venermo and P. Välisuo, Int. J. Biomed. Imaging, 2012, 2012, 26.

38 M. V. Marshall, J. C. Rasmussen, I. C. Tan, M. B. Aldrich, K. E. Adams, X. Wang, C. E. Fife, E. A. Maus, L. A. Smith and E. M. Sevick-Muraca, Open Surg. Oncol. J., 2010, 2, 12-25.

39 X. Wang, G. Ku, M. A. Wegiel, D. J. Bornhop, G. Stoica and L. V. Wang, Opt. Lett., 2004, 29, 730-732.

40 C. Kim, K. H. Song, F. Gao and L. V. Wang, Radiology, 2010, 255, 442-450.

41 A. Hannah, G. Luke, K. Wilson, K. Homan and S. Emelianov, ACS Nano, 2014, 8, 250-259.

42 H. Wang, C. Liu, X. Gong, D. Hu, R. Lin, Z. Sheng, C. Zheng, M. Yan, J. Chen, L. Cai and L. Song, Nanoscale, 2014, 6, 14270-14279.

43 A. Buehler, E. Herzog, D. Razansky and V. Ntziachristos, Opt. Lett., 2010, 35, 2475-2477.

44 W. H. De Jong, W. I. Hagens, P. Krystek, M. C. Burger, A. J. A. M. Sips and R. E. Geertsma, Biomaterials, 2008, 29, 1912-1919.

45 M. Semmler-Behnke, W. G. Kreyling, J. Lipka, S. Fertsch, A. Wenk, S. Takenaka, G. Schmid and W. Brandau, Small, 2008, 4, 2108-2111.

46 N. Khlebtsov and L. Dykman, Chem. Soc. Rev., 2011, 40, 1647-1671. 